\title{
Iron Deficiency and Obesity - Are we Diagnosing with Appropriate Indicators?
}

\section{Défice de Ferro e Obesidade - Estaremos a Diagnosticar com os Indicadores Apropriados?}

\author{
Ana Margarida MONTEIRO $\rrbracket^{1}$, Vera FERNANDES¹, Cláudia MATTA-COELHO¹, Sílvia PAREDES ${ }^{1}$, \\ Maria Lopes PEREIRA', ${ }^{1,2}$, Olinda MARQUES ${ }^{1}$, Marta ALVES ${ }^{1,2}$ \\ Acta Med Port 2018 Sep;31(9):478-482 - https://doi.org/10.20344/amp.8916
}

\section{ABSTRACT}

Introduction: We aim to define the iron deficiency prevalence and eventual differences between obese patients with and without metabolic syndrome.

Material and Methods: Analysis of patients evaluated at multidisciplinary consultation of obesity in our institution between 2013 and $2015(\mathrm{n}=260)$. Iron deficiency: ferritin levels < $15 \mathrm{ng} / \mathrm{mL}$. Exclusion criteria: prior bariatric surgery; lack of ferritin or hemoglobin determinations.

Results: We analyzed data from 215 patients (84.2\% female) with a mean age of $42.0 \pm 10.3$ years. The median body mass index was $42.5(40.0-46.8) \mathrm{kg} / \mathrm{m}^{2}$ and $52.1 \%$ had metabolic syndrome. Iron deficiency was present in $7.0 \%$, with no differences between genders or between patients with or without metabolic syndrome. Hypertension was associated with lower prevalence of iron deficiency. Type 2 diabetes and hypertension patients had higher levels of ferritin. The multivariate analysis showed that metabolic syndrome and increasing body mass index were predictive of higher risk of iron deficiency while hypertension predicted lower odds of iron deficiency. Discussion: The prevalence of iron deficiency was similar in other published studies. Iron deficiency may be underdiagnosed if based only on ferritin concentrations. In our study, diabetes and hypertension appear to contribute to the increase in ferritin levels described in obesity.

Conclusion: Ferritin may not be a reliable index for evaluating iron stores in obese patients, particularly when associated with comorbidities such as type 2 diabetes and hypertension. Further studies are needed to guide the diagnosis and iron supplementation in these patients.

Keywords: Ferritins/deficiency; Iron/deficiency; Metabolic Syndrome; Obesity

\section{RESUMO}

Introdução: Os objetivos foram a determinação da prevalência de défice de ferro e de eventuais diferenças entre os doentes obesos com e sem síndrome metabólica.

Material e Métodos: Análise dos doentes observados na consulta multidisciplinar de obesidade na nossa instituição entre 2013 e 2015 $(n=260)$. Défice de ferro: ferritina < $15 \mathrm{ng} / \mathrm{mL}$. Critérios de exclusão: cirurgia bariátrica prévia, ausência de doseamentos de ferritina e de hemoglobina.

Resultados: Avaliaram-se 215 doentes ( $84,2 \%$ mulheres) com uma idade média de $42,0 \pm 10,3$ anos. O índice de massa corporal mediano foi $42,5(40,0-46,8) \mathrm{kg} / \mathrm{m}^{2}$ e $52,1 \%$ apresentavam síndrome metabólica. O défice de ferro estava presente em $7,0 \%$ sem diferenças entre os géneros e entre os doentes com e sem síndrome metabólica. A hipertensão associou-se a menor prevalência de défice de ferro. Doentes com diabetes tipo 2 e hipertensão apresentaram valores mais elevados de ferritina. Na análise multivariada, a síndrome metabólica e o índice de massa corporal constituíram fatores preditivos de défice de ferro, enquanto a hipertensão se associou a um menor risco.

Discussão: A prevalência de défice de ferro foi similar a estudos previamente publicados. O défice de ferro pode ser subdiagnosticado se baseado apenas nas concentrações de ferritina. No nosso estudo, a diabetes e a hipertensão parecem contribuir para os níveis elevados de ferritina descritos na obesidade.

Conclusão: A ferritina poderá não ser um índice fiável para avaliação de reservas de ferro na obesidade, particularmente quando associada a diabetes tipo 2 e hipertensão. São necessários mais estudos de forma a orientar o diagnóstico e a suplementação com ferro nestes doentes.

Palavras-chave: Ferritinas/deficiência; Ferro/deficiência; Obesidade; Síndrome Metabólica

\section{INTRODUCTION}

Obesity and iron deficiency (ID) are diseases with epidemic proportions and share a strong link. ${ }^{1,2}$ ID with or without anemia is amongst the most commonly reported nutritional deficiencies in patients undergoing bariatric surgery (BS). ${ }^{3}$ ID may worsen the burden of obesity and complicate weight management. Fatigue, depression and reduced exercise capacity associated with ID may reduce the efficacy of behavioral weight management treatments. ${ }^{4-6}$
The etiology of ID in patients with obesity appears to be multifactorial. Although different explanations for ID have been described among obese individuals, the current explanation is the accompanying chronic lowlevel inflammatory state as it reduces iron absorption and increases reticuloendothelial iron sequestration. Support for an inflammatory cause for the ID of obesity results from the observation that serum ferritin concentrations, which

\footnotetext{
1. Departamento de Endocrinologia. Hospital de Braga. Braga. Portugal.

2. Consulta Multidisciplinar de Obesidade. Hospital de Braga. Braga. Portugal.

$\triangle$ Autor correspondente: Ana Margarida Monteiro. anamargaridacmonteiro@gmail.com,

Recebido: 02 de março de 2017 - Aceite: 18 de julho de 2018 | Copyright $\odot$ Ordem dos Médicos 2018
} 
are usually suppressed when body iron stores are low, tend to be high and inversely related to transferrin saturation in obesity., ${ }^{4-9}$ Ferritin, as an acute-phase reactant, is increased in conditions associated with inflammation and previous studies have documented normal or elevated levels of ferritin even in the presence of true iron deficiency. ${ }^{1}$

In contrast, there is increasing evidence supporting the association between elevated iron stores and adverse health outcomes. Elevated ferritin levels have been independently associated and are a predictive factor for metabolic syndrome (MetS), type 2 diabetes (T2DM) and obesity. ${ }^{10-13}$

The iron homeostasis in obesity may be a two-faced clinical condition. On one hand, obesity may promote iron deficiency and on the other hand the presence of a condition termed "dysmetabolic iron overload syndrome" (DIOS) has become the most frequent differential diagnosis for elevated ferritin concentrations in patients with metabolic syndrome (MetS) or nonalcoholic fatty liver disease (NAFLD). DIOS is characterized by increased serum ferritin concentrations with normal or mildly elevated transferrin saturation and true iron overload is rarely found in those patients. ${ }^{5}$

As the iron metabolism remains unclear in these populations, the purposes of this study were to determine the prevalence of ID and evaluate the presence of eventual differences between obese patients with and without metabolic syndrome (MS).

\section{MATERIAL AND METHODS \\ Patients and data collection}

We selected participants in this cross-sectional study among the candidates evaluated at the multidisciplinary obesity clinic at our institution between 2013 and 2015. The multidisciplinary consultation includes endocrinologists, nutritionists, and general surgeons. Patients with BS criteria [body mass index $(\mathrm{BMI})>40 \mathrm{~kg} / \mathrm{m}^{2}$ or $\mathrm{BMI}>35 \mathrm{~kg} / \mathrm{m}^{2}$ with comorbidities] are evaluated preoperatively and followedup after BS.

Exclusion criteria included history of prior BS $(n=33)$ and lack of ferritin and hemoglobin $(\mathrm{Hb})$ determinations obtained at the same time during pre-surgical evaluation (n $=21$ ).

The local ethics committee approved this study.

Clinical, anthropometric, biochemical, and hematological pre-surgical parameters were analyzed. Weight and height were measured in the first visit. Diagnosis of type 2 diabetes (T2DM), hypertension, dyslipidemia, and metabolic syndrome (MetS) were based on medical history and laboratory data.

\section{Laboratory measurements}

All laboratory measurements were performed on fasting blood samples. The biochemical parameters analyzed included measurement of fasting serum glucose, glycosylated hemoglobin ( $\mathrm{HbA} 1 \mathrm{c})$, insulin, total cholesterol (TC), high-density lipoprotein cholesterol (HDL-c), lowdensity lipoprotein cholesterol (LDL-c), triglycerides (TG), hemoglobin, hematocrit, mean corpuscular hemoglobin concentration (MCHC), mean corpuscular volume (MCV), ferritin, transferrin and serum iron. These parameters were measured by standard laboratory techniques used in clinical chemistry laboratories.

\section{Definitions}

According to the WHO definition, ferritin levels under $15 \mathrm{ng} / \mathrm{mL}$ were considered as absolute iron deficiency (ID) and values of hemoglobin $(\mathrm{Hb})$ under $13 \mathrm{~g} / \mathrm{dL}$ and $12 \mathrm{~g} /$ $\mathrm{dL}$ in men and in women, respectively, were considered diagnostic of anemia. ${ }^{14,15}$

The definition of MetS by the updated National Cholesterol Education Program (NCEP) Adult Treatment Panel (ATP) III was used. Therefore, MetS was considered as the presence of any three of the following five traits: (a) abdominal obesity, defined as a waist circumference $\geq 102$ $\mathrm{cm}$ in men and $\geq 88 \mathrm{~cm}$ in women; (b) serum TG $\geq 150 \mathrm{mg} /$ $\mathrm{dL}$ or drug treatment for elevated TG; (c) serum HDL-c < 40 $\mathrm{mg} / \mathrm{dL}$ in men and $<50 \mathrm{mg} / \mathrm{dL}$ in women or drug treatment for low HDL-c; (d) blood pressure $\geq 130 / 85 \mathrm{mmHg}$ or drug treatment for elevated blood pressure; (e) fasting plasma glucose $\geq 100 \mathrm{mg} / \mathrm{dL}$ or drug treatment for elevated blood glucose. ${ }^{16}$

\section{Statistical analysis}

Normal distribution of the variables was evaluated using the Kolmogorov-Smirnov test. Comparisons between groups were performed using $t$ test (normal distribution) and Mann-Whitney test (non-normal distribution) for continuous variables and the $\chi^{2}$ test for categorical variables. The relationships between the continuous variables were examined by the Spearman's linear correlation test.

To assess the variables independently related to ID in all the individuals included in the study, multiple binary regression analyses were performed. ID was considered as the dependent variable and the independent variables were age, sex (male/female), BMI, HbA1c, hypertension (yes/no) and T2DM (yes/no).

Statistical significance was accepted at the level of $p<0.05$. Statistical analyses were performed with the program IBM SSPS version 20.

\section{RESULTS}

This study included 215 patients, 84.2\% ( $n=181)$ females and a mean age of $42.0 \pm 10.3$ years. The median BMI was 42.5 (IQR 40.0-46.8) kg/m² and MetS was present in $52.1 \%(n=112)$ of patients. Table 1 describes the detailed patient's characteristics.

Absolute iron deficiency was present in 7.0\% ( $\mathrm{n}=$ 15) There were no differences between genders $(0.0 \%$ vs $8.3 \% ; p=0.14)$. As showed in Table 2 , we found no differences between patients with or without MetS $(8.0 \%$ vs $5.8 \% ; p=0.52)$. Also, there were no differences between iron metabolism indices and hematological parameters in patients with or without MetS.

We further evaluated eventual differences in each 
element of MetS. We found that patients with T2DM (25.1\%; $\mathrm{n}=54$ ) had higher levels of ferritin (117.5 vs 63.0; $p=0.009)$ although no differences in the prevalence of ID were shown $(3.7 \%$ vs $8.1 \% ; p=0.37)$.

Hypertensive patients $(45.6 \% ; n=98)$ had higher levels of ferritin (83.0 vs 58.0; $p=0.029)$ and lower prevalence of ID (3.1\% vs $10.3 \% ; p=0.04)$.

Between patients with $(n=73)$ and without dyslipidemia $(n=142)$, there were no differences in ferritin levels $(79.0$ vs $64.5 ; p=0.62)$ or in the prevalence of ID ( $7.7 \%$ vs $5.2 \%$; $p=0.76)$.

Positive correlations between ferritin and serum iron $(r=$ $0.38 ; p<0.001)$, glycaemia $(r=0.26 ; p<0.001)$ and insulin $(r=0.19 ; p=0.005)$ were verified. There were no significant correlations between ferritin and BMI $(r=-0.31 ; p=0.651)$ or weight $(r=1.18 ; p=0.083)$.

We performed a logistic regression (Table 3) to establish the effects of age, gender, BMI and the presence of MetS, hypertension, dyslipidemia and T2DM on the probability of having ID. The presence of MetS predicts a higher risk of ID while the presence of hypertension was associated with a lower risk of ID. Increasing BMI was independently associated with ID, and for every unit increase in BMI the odds of ID increases 0.09 .

\section{DISCUSSION}

In our study, ID was present in $7.0 \%$ of patients. This percentage may be underestimated due to the higher values of ferritin reported in patients with chronic inflammation. In our study, diabetes and hypertension appear to contribute

Table 1 - Characteristics of study population $(n=215)$

\begin{tabular}{llll}
\hline Variables & Results & Variables & Results \\
\hline Sex, (\%) (M/F) & M: $15.8 \mathrm{~F}: 84.2$ & Fasting glucose (mg/dL), median (IQR) & $94.0(88.0-107.0)$ \\
Age (years), mean \pm SD & $42.0 \pm 10.3$ & HbA1c (\%), median (IQR) & $5.6(5.3-6.0)$ \\
BMI (kg/m²), median (IQR) & $42.5(40.0-46.8)$ & Insulin (mg/dL), median (IQR) & $14.7(10.1-24.3)$ \\
Weight (kg), median (IQR) & $112.0(100-126.0)$ & Total cholesterol (mg/dL), median (IQR) & $183.0(165.0-215.0)$ \\
MetS, \% (n) & $52.1(112)$ & HDL-c (mg/dL), median (IQR) & $47.0(39.0-54.0)$ \\
Dyslipidemia, \% (n) & $73.0(157)$ & LDL-c (mg/dL), median (IQR) & $112.0(97.0-139.0)$ \\
Hypertension, \% (n) & $45.6(98)$ & Triglycerides (mg/dL), median (IQR) & $118.0(92.0-169.0)$ \\
T2DM, \% (n) & $25.1(54)$ & C-reactive protein (mg/L), median (IQR) & $8.02(4.0-13.6)$ \\
\hline
\end{tabular}

M: male; F: female; SD: standard deviation; BMI: body mass index; IQR: interquartile range; MetS: metabolic syndrome; T2DM: type 2 diabetes mellitus; HbA1c: glycated hemoglobin; HDL-C: high density lipoprotein cholesterol; LDL-c: low density lipoprotein cholesterol

Table 2 - Hematological parameters according to the presence of Metabolic Syndrome (MetS)

\begin{tabular}{lllll}
\hline Variables & MetS $(\mathbf{n}=\mathbf{1 1 2})$ & No MetS $(\mathbf{n}=103)$ & All $(\mathbf{n}=\mathbf{2 1 5})$ & $p$ value \\
\hline Hemoglobin (g/dL), median (IQR) & $13.6(13.1-14.6)$ & $13.9(13.2-14.5)$ & $13.7(13.1-14.5)$ & $0.514 \dagger$ \\
Hematocrit (\%), median (IQR) & $40.4(39.0-42.5)$ & $40.9(38.8-42.7)$ & $40.6(38.9-42.6)$ & $0.878 \dagger$ \\
MCHC (g/dL), median (IQR) & $33.9(33.2-34.6)$ & $34.0(33.3-34.6)$ & $33.9(33.3-34.6)$ & $0.461 \dagger$ \\
MCV (fl), median (IQR) & $86.1(83.2-88.9)$ & $85.4(82.6-87.7)$ & $85.5(83.0-88.3)$ & $0.09 \dagger$ \\
C-reactive protein (mg/L) median (IQR) & $7.74(3.9-11.6)$ & $9.19(4.5-14.4)$ & $8.02(4.0-13.6)$ & $0.16 \dagger$ \\
Ferritin (ng/dL), median (IQR) & $83.0(36.3-185.5)$ & $64.0(35.0-123.0)$ & $73.0(36.0-155.0)$ & $0.16 \dagger$ \\
Transferrin (mg/dL), median (IQR) & $281.0(248.8-316.5)$ & $281.0(263.0-315.0)$ & $281.0(258.0-315.5)$ & $0.253 \dagger$ \\
Iron (ug/dL), median (IQR) & $75.0(55.3-91.0)$ & $73.0(56.0-100.0)$ & $74.0(56.0-94.0)$ & $0.825 \dagger$ \\
Iron deficiency, \% (n) & $8.0(9)$ & $5.8(6)$ & $7.0(15)$ & $0.52^{* *}$ \\
Anemia, \% $(\mathrm{n})$ & $7.1(8)$ & $4.9(5)$ & $6.0(13)$ & $0.48^{* *}$ \\
\hline
\end{tabular}

IQR: interquartile range; MCHC: mean corpuscular hemoglobin concentration; MCV: mean corpuscular volume; † Mann-Whitney U test; ** Fisher's exact test

Table 3 - Analysis of predictors of iron deficiency (Logistic regression model)

\begin{tabular}{llllc}
\hline Variables & Regression coefficient & OR & $p$ value & 95\% C.I. for OR \\
\hline Age & 0.038 & 1.039 & 0.274 & $0.97-1.113$ \\
Gender (female) & 18.271 & 86072754.4 & 0.998 & - \\
BMI $\left(\mathrm{kg} / \mathrm{m}^{2}\right)$ & 0.094 & 1.099 & 0.035 & $1.007-1.199$ \\
Metabolic syndrome & 1.632 & 5.113 & 0.030 & $1.17-22.357$ \\
Hypertension & -2.394 & 0.091 & 0.008 & $0.016-0.533$ \\
T2DM & -1.357 & 0.257 & 0.137 & $0.043-1.542$ \\
Dyslipidemia & -0.140 & 0.870 & 0.863 & $0.179-4.234$ \\
\hline
\end{tabular}

BMI: body mass index T2DM: type 2 diabetes mellitus 
to the increase in ferritin levels described in obesity. It is important to understand that hyperferritinaemia does not necessarily mean the presence of true iron overload.

A comparable prevalence $(8.7 \%)$ of iron deficiency were reported in the studies of Careaga et al and Sánchez et $a^{\beta, 17}$ Other studies have reported varying ID prevalence's in patients prior BS and those differences can be explained, in part, by the different criteria applied to define ID. ${ }^{18,19}$

According to our logistic regression model, a higher BMI was independently associated with a higher risk of ID. This finding is in agreement with a recent meta-analysis that showed that obesity was associated with ID, although studies with a ferritin-based diagnosis of ID more frequently conclude that obesity is not associated with ID. ${ }^{1}$ The etiology of obesity associated ID remains unclear and several mechanisms have been proposed as consumption of a poorly balanced diet, increased iron requirements due to larger blood volume and size and, more recently, hepcidinmediated iron sequestration. ${ }^{1,7}$ We could not demonstrate a correlation between BMI and ferritin levels, suggesting minimal chronic inflammation in our obese patients or minimal influence of chronic inflammation in ferritin levels. Considering C-reactive protein has low specificity and we lack levels of ultrasensitive C-reactive protein, we cannot infer about inflammation status.

Our study demonstrated that MetS is associated with a higher odds of ID, which is in contrast with the studies that reported higher ferritin levels in patients with MetS probably due to low chronic inflammation. ${ }^{20-22}$ In fact, although without statistical differences due to sample size and overall lower prevalence of ID, patients with MetS criteria in our study had higher median levels of ferritin and more patients had ID. This could reflect the complexity of iron metabolism in low chronic inflammation status and that ferritin levels may not be a reliable index to diagnose ID in those patients.

Patients with T2DM had higher levels of ferritin and we found a positive correlation between ferritin and glucose and insulin. This is in agreement with published literature as several studies also have reported higher levels of ferritin in patients with DM2. Moreover, prospective studies have shown that ferritin concentrations independently predict the development of T2DM. ${ }^{23-25}$ However, T2DM was not independently associated with the risk of ID in our logistic regression model.

Also in agreement with other studies, our patients with hypertension had higher ferritin levels and consequently, lower prevalence of ID. We demonstrated that hypertension was independently associated with a lower risk of ID, which is in agreement with the higher levels reported in hypertensive patients. An independent association between higher ferritin levels and the risk of hypertension have also been reported. ${ }^{26,27}$

\section{Limitations}

This study reflects a small sample of patients evaluated retrospectively and without a control group. In the future, prospective randomized control trials could help to establish a cause-effect relation.

The absence of determinations of ultrasensitive C-reactive protein and other iron metabolism indices, as hepcidin and soluble transferrin receptor, limits our interpretation of the results and evaluation of the deficit or iron overload.

\section{CONCLUSION}

The iron metabolism in these patients is heterogeneous, complex, and still not fully understood.

According to our results, ferritin may not be a reliable index for evaluating iron stores in obese patients, particularly when associated with comorbidities such as T2DM and hypertension. ID may be underdiagnosed if based only on ferritin concentrations.

Evaluation and replenishment of ID in patients with obesity are important prior to BS to minimize the deterioration after surgery. However, it has been advocated that iron excess increased the risk of important comorbidities. Also, several studies have showed that the mechanisms for iron absorption are disrupted in obesity. As both iron deficiency and overload may have detrimental effects further studies are needed to guide the diagnosis of ID and the eventual need of iron replenishment. ID diagnosis should be based on other indices not affected by the acute-phase response in order to differentiate true deficits from secondary changes to states of chronic inflammation.

\section{ACKNOWLEDGMENTS}

The authors thank all elements of multidisciplinary consultation of obesity in Hospital de Braga that enabled this study.

\section{PROTECTION OF HUMAN AND ANIMAL SUBJECTS}

The authors declare that the research procedures were performed according to the regulations of the institution's ethics committee and the Code of Ethics of the World Medical Association (Declaration of Helsinki).

\section{CONFIDENTIALITY OF DATA}

The authors declare that they have followed the protocols of their work center regarding the publication of data from patients.

\section{CONFLICT OF INTEREST}

No conflict of interest has been declared by any author.

\section{FUNDING}

The authors declare the absence of financial support. 


\section{REFERENCES}

1. Zhao L, Zhang $X$, Shen $Y$, Fang $X$, Wang $Y$, Wang F. Obesity and iron deficiency: A quantitative meta-analysis. Obes Rev. 2015;16:1081-93.

2. Becker C, Orozco M, Solomons NW, Schümann K. Iron metabolism in obesity: how interaction between homoeostatic mechanisms can interfere with their original purpose. Part II: epidemiological and historic aspects of the iron/obesity interaction. J Trace Elem Med Biol. 2015;30:202-6.

3. Careaga M, Moizé V, Flores L, Deulofeu R, Andreu A, Vidal J. Inflammation and iron status in bariatric surgery candidates. Surg Obes Relat Dis. 2015;11:906-11.

4. Cheng HL, Bryant C, Cook R, O'Connor H, Rooney K, Steinbeck K. The relationship between obesity and hypoferraemia in adults: A systematic review. Obes Rev. 2012;13:150-61.

5. Aigner E, Feldman A, Datz C. Obesity as an emerging risk factor for iron deficiency. Nutrients. 2014;6:3587-600.

6. Peyrin-Biroulet L, Williet N, Cacoub P. Guidelines on the diagnosis and treatment of iron deficiency across indications: a systematic review. Am J Clin Nutr. 2015;102:1585-94.

7. Yanoff LB, Menzie CM, Denkinger B, Sebring NG, McHugh T, Remaley AT, et al. Inflammation and iron deficiency in the hypoferremia of obesity. Int J Obes. 2007;31:1412-9.

8. Zafon C, Lecube A, Simó R. Iron in obesity. An ancient micronutrient for a modern disease. Obes Rev. 2010;11:322-8.

9. Fernández-Real JM, Manco M. Effects of iron overload on chronic metabolic diseases. lancet Diabetes Endocrinol. 2014;2:513-26.

10. Abril-Ulloa V, Flores-Mateo G, Solà-Alberich R, Manuel-y-Keenoy B, Arija V. Ferritin levels and risk of metabolic syndrome: meta-analysis of observational studies. BMC Public Health. 2014;14:483.3

11. Yoo K-D, Ko S-H, Park J-E, Ahn Y-B, Yim HW, Lee W-C, et al. High serum ferritin levels are associated with metabolic risk factors in nonobese Korean young adults: Korean National Health and Nutrition Examination Survey (KNHANES) IV. Clin Endocrinol. 2012;77:233-40.

12. Ledesma M, Hurtado-Roca $Y$, Leon M, Giraldo P, Pocovi M, Civeira $F$, et al. Association of ferritin elevation and metabolic syndrome in males. Results from the Aragon Workers' Health Study (AWHS). J Clin Endocrinol Metab. 2015;100:2081-9.

13. Park SK, Choi WJ, Oh CM, Kim J, Shin H, Ryoo JH. Association between serum ferritin levels and the incidence of obesity in Korean men: A prospective cohort study. Endocr J. 2014;61:215-24.
14. Haemoglobin concentrations for the diagnosis of anaemia and assessment of severity. [cited 2016 Mar 12]. Available from: http://www. who.int/vmnis/indicators/haemoglobin.pdf

15. Serum ferritin concentrations for the assessment of iron status and iron deficiency in populations. [cited 2016 Mar 12]. Available from: http:// www.who.int/vmnis/indicators/serum_ferritin.pdf

16. Grundy SM, Cleeman JI, Daniels SR, Donato KA, Eckel RH, Franklin $\mathrm{BA}$, et al. Diagnosis and management of the metabolic syndrome: an American Heart Association/National Heart, Lung, and Blood Institute Scientific Statement. Circulation. 2005;112:2735-52.

17. Sánchez A, Rojas P, Basfi-fer K, Carrasco F, Inostroza J, Codoceo J, et al. Micronutrient Deficiencies in Morbidly Obese Women Prior to Bariatric Surgery. Obes Surg. 2016;26:361-8.

18. Salgado W, Modotti C, Nonino CB, Ceneviva R. Anemia and iron deficiency before and after bariatric surgery. Surg Obes Relat Dis. Elsevier; 2014;10:49-54.

19. Khanbhai M, Dubb S, Patel K, Ahmed A, Richards T. The prevalence of iron deficiency anaemia in patients undergoing bariatric surgery. Obes Res Clin Pract. 2015;9:45-9.

20. Datz C, Felder TK, Niederseer D, Aigner E. Iron homeostasis in the Metabolic Syndrome. Eur J Clin Invest. 2013;43:215-24.

21. Kilani N, Vollenweider P, Waeber G. Nutrition , Metabolism \& Cardiovascular Diseases Iron metabolism and incidence of metabolic syndrome. Nutr Metab Cardiovasc Dis. 2015;1-8.

22. Leiva E, Mujica V, Sepúlveda P, Guzmán L, Núñez S, Orrego R, et al. High Levels of Iron Status and Oxidative Stress in Patients with Metabolic Syndrome. Biol Trace Elem Res. 2013;151:1-8

23. Lecube A, Hernández C, Pelegrí D, Simó R. Factors accounting for high ferritin levels in obesity. Int J Obes. 2008;32154:1665-9.

24. Simcox JA, McClain DA. Iron and diabetes risk. Cell Metab. 2013;17(3):329-41.

25. Jehn M, Clark JM, Guallar E. Serum ferritin and risk of the metabolic syndrome in U.S. adults. Diabetes Care. 2004;27:2422-8.

26. Ryoo J-H, Kim SY, Park SK, Kim E, Park S-J, Yu JI, et al. The incidental relationship between serum ferritin level and hypertension. Int J Cardiol. 2014;183:258-62.

27. Kim MK, Baek KH, Song K-H, Kang M II, Choi JH, Bae JC, et al. Increased serum ferritin predicts the development of hypertension among middle-aged men. Am J Hypertens.2012;25:492-7. 